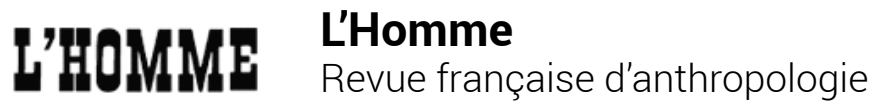

207-208 | 2013

Un miracle créole?

\section{Créolisation et quête de reconnaissance}

Creolization and the Quest for Recognition

\section{Raymond Massé}

\section{(2) OpenEdition}

\section{Journals}

\section{Édition électronique}

URL : https://journals.openedition.org/lhomme/24690

DOI : 10.4000/lhomme.24690

ISSN : 1953-8103

\section{Éditeur}

Éditions de l'EHESS

\section{Édition imprimée}

Date de publication : 12 novembre 2013

Pagination : 135-157

ISSN : 0439-4216

\section{Référence électronique}

Raymond Massé, «Créolisation et quête de reconnaissance », L'Homme [En ligne], 207-208| 2013, mis en ligne le 05 novembre 2015, consulté le 21 septembre 2021. URL : http://journals.openedition.org/ Ihomme/24690 ; DOI : https://doi.org/10.4000//homme.24690 


\title{
Créolisation et quête de reconnaissance
}

\author{
Raymond Massé
}

\author{
"L'homme n'est humain \\ que dans la mesure où il veut simposer à un autre homme, \\ afin de se faire reconnaître par lui. \\ Tant quil n'est pas effectivement reconnu par l'autre, \\ c'est cet autre qui demeure le thème de son action. \\ C'est de cet autre, c'est de la reconnaissance par cet autre, \\ que dépendent sa valeur et sa réalité humaines" \\ Frantz Fanon (1952: 177-178).
}

\section{L}

LA CRÉOLISATION a pris aux Antilles françaises autant d'acceptions qu'il y a de formes reconnues de créolités. La créolité est définie souvent comme courant littéraire, espace de création littéraire, ethnopoétique, mythe (Perret 2001) ou, parfois, comme idéologie ou mouvement sociopolitique. Bien sûr, tous les spécialistes s'entendent pour recadrer la créolisation dans le contexte colonial et pour reconnaître le rôle central joué par l'esclavage et l'économie de plantation qui lui ont servi de creuset social et économique. Une élite intellectuelle y verra tantôt une préfiguration du "Tout-Monde» (Glissant 1997), tantôt la base d'un programme politique panantillais qui mérite éloge (Bernabé, Chamoiseau \& Confiant 1989). À la différence de certains Antillais anglophones qui considèrent le concept de créolisation comme un "signifiant flottant", servant à masquer les divisions ethniques internes dans le discours politique (Khan 2007), les Antillais francophones ne le soumettent que rarement à un tel exercice de déconstruction.

La créolisation est une donnée, une réalité parfois essentialisée et, dès lors, récupérable pour divers usages sociaux et politiques. Une réification essentiellement discursive, célébrée à satiété dans la littérature créole, menacée par la folklorisation, ne débouche qu'exceptionnellement aujourd'hui (comparativement à la situation prévalente au milieu du $\mathrm{XX}^{\mathrm{e}}$ siècle) sur de véritables analyses empiriques de ses manifestations et de ses ancrages dans les sphères de la vie quotidienne. La créolité et la créolisation risquent de devenir sujets de discours et d'usages politiques, avant d'être objets d'études anthropologiques et sociopolitiques. 
Je m'attacherai donc ici à proposer deux pistes de réflexion, voire deux chantiers de recherche, susceptibles de stimuler les analyses sur la créolisation. Le premier sera celui d'une anthropologie de la créolisation; l'objectif est alors de définir empiriquement les contours et les multiples composantes de ce concept. Le second chantier sera celui d'une analyse critique des forces politiques qui l'alimentent et qui en assurent, encore aujourd'hui, le dynamisme. Si les grilles de lecture en termes de conflits de classe ou celles, dans la foulée des études postcoloniales, en termes de conflits centre/périphérie, aident à la compréhension de la créolisation à l'époque coloniale, elles peuvent difficilement expliquer la vitalité de ce processus tout au long du $\mathrm{XX}^{\mathrm{e}}$ siècle. En m'inspirant du paradigme de la reconnaissance qui, à la suite des travaux de Axel Honneth, a inspiré une partie de la recherche en sciences sociales, j'avancerai l'hypothèse selon laquelle la quête de reconnaissance, le refus du mépris et le ressentiment envers la Métropole sont les moteurs fondamentaux du processus de créolisation dans la Martinique du XXI ${ }^{\mathrm{e}}$ siècle.

\section{Créolisation : fondements empiriques et usages sociopolitiques}

Dans le prolongement de la thèse soutenue par Ulf Hannerz (1987) suivant laquelle le monde est "en processus de créolisation", plusieurs chercheurs ont retenu ce concept pour décliner les multiples modalités de métissage ou d'hybridation culturelle, et ce, bien au-delà des sociétés traditionnellement considérées comme "créoles». Des "situations créoles " ont, en effet, été repérées en Colombie, en Argentine, voire au Japon (Célius 2006). Stephan Palmié (2006) a confronté les applications de ce concept dans des recherches portant sur des régions aussi éloignées de l'univers caribéen que la Gaule antique, l'Italie du Nord, l'Inde du Sud ou les îles Salomon. La métaphore de la créolisation, qui tantôt englobe tantôt déborde les concepts d'acculturation, de transnationalisme ou de mondialisation, est généralement utilisée pour rendre compte, à partir de la naissance de langues issues du creuset colonial, des métissages raciaux ou des mécanismes sous-jacents aux syncrétismes religieux. Le concept permet aussi de rendre compte de la "créolisation" des savoirs et des pratiques de soins de santé dans le cadre de "mondes créolisants» (Bibeau 1997), de la "créolisation" des catégories diagnostiques psychiatriques (Kleinman 1997), ou de l'émergence de la débrouillardise comme produit typique d'une "créolisation" de l'économie martiniquaise (Browne 2004). Devons-nous alors suivre James Clifford (1988: 173) affirmant que «nous sommes tous Caribéens aujourd'hui »? Ou plutôt Stephan Palmié (2006) 
qui dénonce un usage abusif du concept de créolisation, ne serait-ce que comme métaphore?

\section{Créolisation et hybridation : apports et limites de la métaphore}

La créolisation est tout à la fois métaphore de l'ouverture à l'autre, de la tolérance intégratrice, de la résilience face aux forces d'assimilation, de la résistance face au mépris (néo)colonial, de l'énergie créatrice et de l'identité sculptée dans la diversité. Elle est, enfin, métaphore de la culture elle-même, en tant que principe intégrateur, forme structurante et modèle génératif de symboles et de pratiques. Il serait certainement vain de s'opposer à son usage métaphorique. Mais une telle extension de la créolisation se doit néanmoins d'établir clairement qu'il s'agit bel et bien d'une métaphore lorsqu'on l'applique à des contextes historiques et à des problématiques qui n’ont que peu de points communs avec des sociétés marquées par les colonialismes européens et l'esclavage. En tant que concept opératoire, la créolisation devrait être réservée, croyons-nous, à la désignation du processus complexe de production de sociétés et de cultures "créoles ", soit des sociétés issues du brassage racial et culturel mettant en présence obligatoirement (mais non exclusivement) des populations africaines et européennes, dans le contexte de sociétés de plantation.

Plusieurs analystes s'entendent pour définir, comme conditions nécessaires de la créolisation, une diversité culturelle et raciale fondatrice, un métissage à la fois physique et culturel, l'invention d'une langue créole, l'existence de rapports asymétriques de couleur (ou raciaux) expliquant la reproduction des inégalités sociales et l'émergence d'une nouvelle identité collective métissée. Jean-Luc Bonniol, en particulier, identifie trois composants fondamentaux des "situations créoles »: l'hétéronomie engendrée par l'économie de plantation "à moteur externe", orientée vers la satisfaction des seuls besoins de la Métropole; un flux de peuplement externe et la disparition des populations autochtones; enfin, la diversité des apparences physiques maintenue par un préjugé de couleur. La créolisation devient alors la constante recherche d'équilibre entre deux forces opposées que sont la reproduction des inégalités comme force passive et la dynamique des métissages, intégration et innovation (2006: 51-52). L'extension du concept de créolisation, par exemple aux sociétés marquées par un " colonialisme interne " face à leurs populations autochtones, apparaît alors problématique. Bien que les conditions nécessaires mentionnées plus haut soient présentes, elles ne sont alors pas suffisantes. La dynamique politique propre au colonialisme de plantation differe de celle qui conduit à la marginalisation et à la stigmatisation sociale des populations autochtones, en 
Australie ou au Canada, par exemple (pourrait-on parler de créolisation pour les Inuits)? Les risques de déqualification du concept de créolisation sont importants. Selon Aisha Khan, " au mieux, les nouvelles acceptions du concept de créolisation, comme métaphore de la créativité, de l'agentivité et de l'empowerment de peuples dominés, le rendent, dans plusieurs cas, superflu» (2001: 272, ma traduction).

Il ne suffit donc pas de constater que le monde moderne se présente moins comme un processus d'homogénéisation culturel que comme "une tendance au remplacement d'une diversité par une autre» pour en déduire, comme le fait Hannerz (1987 : 552), que le monde est désormais créole. Nous suggérons de réserver l'usage du concept de créolisation pour décrire le processus spécifique d'hybridation raciale et culturelle produisant des sociétés "créoles" évoluant sur un continuum identitaire (Hintzen 2002). Le concept d'hybridation culturelle, pour sa part, s'avère un concept alternatif moins connoté par le passé colonial et l'asservissement des populations noires. Bien qu'il fasse lui-même objet de multiples usages et définitions (Orlave 2007), le concept d'hybridation est plus apte à rendre compte de la perméabilité des catégories ethniques, du potentiel créatif et génératif des "rencontres entre cultures" ou des mécanismes de construction identitaire dans les sociétés pluri-ethniques contemporaines.

La créolisation n'en demeure pas moins un processus complexe et polymorphe. Comme toute forme d'hybridation, elle se réfere, selon Nestor García Canclini (1995), à trois processus complémentaires : le mélange de groupes qui organisent les processus culturel, la déterritorialisation des processus symboliques et l'expansion des cultures métissées. La créolisation renvoie également à quatre dynamiques imbriquées et en tension : a) l'assimilation ou amalgamation de cultures minoritaires, dominées ou disqualifiées; b) l'acculturation, en tant que processus induisant l'imposition d'éléments culturels de la part d'une culture dominante; c) la résistance, en tant que phénomène de repli identitaire visant la préservation de marqueurs identitaires centraux mais, tout autant d) la création de nouveaux éléments culturels censés traduire l'«identité " du groupe. La créolisation ne peut donc être considérée comme un processus concerté, conduisant à un simple enrichissement mutuel et symétrique des cultures en présence. Les processus d'assimilation, d'acculturation et de résistance soulignent, au contraire, la dissymétrie dans les rapports de force entre les groupes ethniques et sociaux. Une telle approche multidimensionnelle du concept réduit les dangers de surinterprétation et donne des définitions de la créolisation, chacune couvrant un pan de la réalité complexe à laquelle elle se rapporte. 


\section{Études empiriques des contenus de la créolité}

Les conditions nécessaires définies plus haut sont-elles suffisantes pour saisir la complexité du concept de créolisation? Nous pensons, avec plusieurs auteurs (Khan 2007 ; Palmié 2006 ; Harris \& Rampton 2002), que l'absence de véritables assises empiriques du concept de créolisation risque de le dépouiller de tout fondement. Ce manque de connaissances concrètes quant à sa nature et aux conditions de son évolution explique, en partie, les dérives dans les usages métaphoriques qui en sont faits. Bien sûr, on reconnaitra aisément que les sociétés " créoles " ont été des creusets culturels dans lesquels des descendants d'esclaves africains, des Européens (Français, Espagnols, Portugais, Anglais, Hollandais), des Indiens, des Amérindiens ont été en contact. Mais dans quelle mesure, et principalement dans quels domaines de la vie sociale et culturelle, les "fusions", échanges et mixités continuent-ils d'opérer aujourd'hui? Qu'en est-il de la mécanique précise de la créolisation dans des champs spécifiques, tels la famille, le magico-religieux, les rapports sociaux de solidarité, les rapports de couleur ou les rapports homme-femme? Quels étaient les composants de base des cultures "africaines ", "coolies" et européennes qui sont, encore aujourd'hui, soumis au métissage? Quels sont les produits proprement créoles de ce processus, du point de vue des valeurs, de l'organisation sociale, des pratiques religieuses ou des relations intrafamiliales? L'anthropologie contemporaine peut compter sur un riche héritage d'études empiriques (Herskovits, Wagley, Mintz, Métraux, Bastide, Ortiz, Benoist, Chivallon) portant sur diverses institutions sociales créolisées (famille, Église, pratiques magico-religieuses...) qui ont proposé des réponses partielles et historiquement situées à ces questions. Malheureusement, au cours des dernières décennies, peu d'analyses empiriques sont venues enrichir nos connaissances sur la "nature » de la créolité contemporaine, et ce, dans le respect des nouveaux acquis épistémologiques de l'anthropologie face au réductionnisme des empirismes, au culturalisme naïf et aux relectures postmodernes de la culture et de la mondialisation. Les dangers aujourd'hui reconnus du descriptif ethnographique essentialisant, des surinterprétations et du subjectivisme du chercheur ne doivent pas devenir des freins à l'actualisation des marqueurs de la créolité. Et surtout, au-delà des théories séduisantes qui en font l'emblème de la créativité ouverte, peu d'études de terrain permettent de confirmer l'hypothèse faisant du modèle de la créolisation un processus spécifique se démarquant de tous les autres processus de changements culturels (emprunt, acculturation, assimilation, syncrétisme, symbiose...), qui façonnent les contacts entre cultures ${ }^{1}$.

1. Un pas en ce sens a néanmoins été franchi par les auteurs de l'ouvrage collectif sur les .../... 
Les fondements empiriques de la créolité constituent toujours le maillon faible de l'analyse de la créolisation (Allen 1998) qui devrait être abordée comme "un objet d'étude plutôt que comme un outil pour l'enquête anthropologique» (Palmié 2006 : 448). L’enjeu principal demeure celui d'en aborder les modalités d'expression dans les conditions concrètes d'existence. Ici, l'ethnographie de la créolisation n'est pas une alternative, mais bien une approche complémentaire de l'analyse des violences structurelles qui la façonnent.

Il en va de même pour le contenu de la créolité. On risque de ne voir, dans l'Éloge de la créolité, de Bernabé, Chamoiseau et Confiant, qu'une "liste rhétorique de souhaits" plutôt qu'une "analyse de la créolisation sur le terrain»(Khan 2001: 282, ma traduction), voire un «dernier recours désespéré contre la décréolisation menant à la plénitude réelle ou imaginée d'un 'an tan lontan'" (Burton 1993: 23, ma traduction). D'ailleurs, les multiples revendications d'une identité créole demeurent floues dans leur contenu. Quelles seraient les composantes de cette créolité au début du XXI siècle? Même si Patrick Chamoiseau, par exemple, déplore que les nouvelles formes de domination nous "conduisent à adopter des valeurs et des comportements qui ne sont pas les nôtres " (1998: 48), rien n'est dit sur ces valeurs proprement créoles. Pas plus d'ailleurs que sur celles qui seraient proprement étrangères à la créolité. La justice sociale, la consommation ostentatoire, l'accès aux soins de santé, l'égalité des sexes, le respect de l'autre, l'autonomie, la solidarité, l'entraide, la responsabilité, la valorisation de la famille ou la lutte contre le racisme doivent-ils être considérés comme des valeurs métropolitaines, américaines ou proprement martiniquaises? Malheureusement, aucune étude empirique ne permet de faire le point sur les valeurs et pratiques sociales " martiniquaises ", "créoles » ou "antillaises », ce qui n’empêche pas les revendications autonomistes de s'en faire les défenseurs.

\section{La créolisation : entre essentialisme et postmodernité}

Le discours sur la créolisation donne souvent lieu à des critiques lui reprochant son approche essentialiste de la culture. Plusieurs analystes ont vu dans les sociétés créoles traditionnelles des préfigurations de la post-

[Suite de la note 1] Situations créoles. Invités à réfléchir sur la caractérisation du monde créole et à " analyser les circonstances dans lesquelles se retrouvent des acteurs sociaux, les relations concrètes qui unissent ces derniers à leurs milieux, les données qui caractérisent leurs rapports aux autres, leur évolution, leurs actions» (Célius 2006 : 11), les contributeurs ont esquissé les critères définitionnels de la créolité, et surtout les mécanismes et les forces qui sont en jeu dans diverses situations «nationales", tout autant que dans les processus d'auto-désignation ou d'étiquetage en tant que « créoles». Se trouvent alors dessinés les pourtours d'un large programme de recherche à venir. 
modernité et du pluralisme culturel. La créolisation «met en rapport le divers, tout en maintenant l'identité"(Glissant 1997: 178). Dans ce nouveau "Tout-Monde», les identités ne seraient plus fixes; la créolité serait moins une nature composite achevée qu'un «processus transculturel de transformation». Toujours en mouvement, la créolité ne peut être un produit «fini » du colonialisme. Les auteurs de l'Éloge, quant à eux, martèlent qu'il s'agit d'une identité ouverte, en constante évolution et « [récusent] les dérives de localisme ou de nombrilisme " que certains semblent lui accoler (Bernabé, Chamoiseau \& Confiant 1989: 41). Cette créolité préfigurerait l'hybridation culturelle accélérée par la mondialisation.

Or, paradoxalement, ces caractéristiques en viennent à être présentées comme la «nature » de la créolité, s'inscrivant de fait dans une perspective qui se révèle essentialiste. Le processus de créolisation « est réputé produire des personnes tout particulièrement équipées pour être ouvertes, souples, agiles et spécialement douées pour la nuance, le langage, l'ambiguïté, la contradiction et l'ironie ", suggèrent Eye Stoddard et Grant Cornwell (1999 : 338, ma traduction). Produit de la créolisation, la créolité court alors le risque d'être considérée comme un produit achevé de l'histoire coloniale. Alors que la créolité prend l'allure d'une autochtonéité, la créolisation s'exprime comme processus d'indigénisation identitaire. Les risques d'essentialisation et de réification sont dès lors importants. C'est au nom d'une telle créolité magnifiée que certains revendiquent une reconnaissance comme «peuple». En réalité, rappelle Aisha Khan :

«[...] le concept de créolisation est fondamentalement paradoxal: plus on tente de définir la diversité que le créole représente, plus on en fait une catégorie statique (en opposition à fluide), prédictive (en opposition à contingente) et monolithique (en opposition à multidimensionnelle)» (2001:278, ma traduction).

Dans quelle mesure la créolité ne sert-elle pas, dès lors, entre autres finalités, à entretenir les frontières identitaires entre Antillais et Métropolitains ? Et, derrière cette essentialisation d'une créolité, n'y a-t-il pas un risque de culturalisation des débats politiques? C'est à un tel questionnement politique du concept de créolisation que se livrent plusieurs chercheurs antillais anglophones.

\section{La lecture sociopolitique anglo-saxonne}

Alors qu'aux Antilles françaises, la créolisation est présentée tantôt comme le lieu d'une résistance créatrice, tantôt comme un produit culturel préfigurant le monde postmoderne, aux Antilles anglaises, ce concept fait principalement l'objet d'une analyse sociopolitique critique. La différence de traitement est importante : un romantisme littéraire face 
à une identité en quête de reconnaissance, d'un côté, une déconstruction critique de ses fonctions idéologiques, de l'autre. Certains voient dans les théories de la créolisation, soit un "simple miroir des conditions fondamentales qu'elles cherchent à dénoncer et à supplanter" (Palmié 2002 : 448), soit un masque idéologique dissimulant les affres du colonialisme. Pour d'autres, le discours créole " a fonctionné dans l'intérêt des puissants, qu'ils soient représentés par les élites coloniales ou nationalistes [...]. Il pave la voie aux discours racialisés de la différence sur lesquels repose la légitimité du pouvoir et de l'exploitation coloniale» (Hintzen 2002: 477, ma traduction). Les discours sur la créolisation ne serviraient qu’à minimiser, par une sorte de "fusion cognitive», la réalité des différences raciales. Or, si la créolité exprime la diversité, elle exprime surtout les modalités de sa construction. La vraie question devrait alors être : "quelle sorte de signification prend la différence dans divers contextes; à quels moments la "culture" est-elle un enjeu politique?» (Khan 2001 : 293, ma traduction) et quels intérêts de classe sert-elle? Ne risque-t-elle pas de devenir, indirectement, un mécanisme d'institutionnalisation de la différence entre les Créoles et les non-Créoles? Autrement dit, souligne Aisha Khan, se référant aux conflits entre Trinidadiens d'origine indienne et africaine,

"[...] on peut suggérer que la créolisation est un concept "bon à penser" précisément parce qu'elle constitue une position sécurisée plutôt que quelque chose qui subvertit vraiment. Elle serait en partie une fiction bourgeoise du leadership politique dans lequel l'optimisme téléologique de la rhétorique nationaliste réaffirme le discours normatif sur la différence, masquant les tensions et les contradictions de classe et autres formes d'inégalités» (2007: 658, ma traduction).

Aux Antilles anglophones, non seulement remet-on fréquemment en question les approches essentialistes, réifiantes de la créolité, mais on voit dans le concept de créolisation une catégorie normative qui ramène toute réflexion sur la(les) créolité(s) dans le droit chemin du creuset colonial et des métissages biologiques et culturels. Ainsi, pour Aisha Khan (2001), dans le cas trinidadien, la créolisation et la notion de "société arc-en-ciel » et de culture callaloo (métisse d'origines indienne et africaine) font surtout partie d'une rhétorique politique stratégique de l'harmonie et de la tolérance, visant à masquer les rapports ethniques et politiques asymétriques.

Un premier constat qui ressort clairement de ces divers discours, francophones et anglophones, sur la créolisation est la faiblesse des assises empiriques permettant de définir les contours d'une culture créole (par exemple martiniquaise). Plusieurs questions, fondamentales à notre avis, doivent alors être posées. Au-delà des «éloges » et des usages politiques qui peuvent en être faits, le processus de créolisation est-il un processus 
continu marqué par la symbiose entre les cultures «fondatrices", ou doiton parler de stades spécifiques de ce processus? Peut-on soutenir qu'il existerait deux stades principaux de la créolité : un stade initial marqué, du XVII ${ }^{e}$ au début XXe siècle, par la rencontre des cultures africaines et des cultures européennes (françaises, anglaises et espagnoles principalement), puis un second stade, plus contemporain, marqué par l'évolution de cette " culture créole " première sous l'influence de la culture américaine et des nouveaux avatars de la culture postmoderne? Peut-on encore aujourd'hui parler de créolisation pour évoquer le processus d'évolution culturelle par ailleurs caractéristique de toutes les cultures contemporaines? S’il y a eu coupure dans la créolisation, à quelle période de l'histoire et sous l'influence de quels facteurs (abolition de l'esclavage, fin des plantations, départementalisation ?), la créolisation s'est-elle muée de forme spécifique d'hybridation (répondant aux conditions nécessaires définies plus haut), en "simple» évolution culturelle propre à toute société en contexte de mondialisation? La périodisation établie par Delphine Perret (2001) dans la théorisation de la créolité, d'abord "classique ", "[née] du mouvement nationaliste, identitaire, associé à la défense de la langue et de la culture créole" (2001: 13), devenant ensuite une "créolité plus ouverte", marquée par une sensibilité à la mondialisation, est-elle suffisante pour rendre compte de l'évolution de ce concept?

D'autres questions de recherche interpellent les sciences sociales. La créolité est-elle une caractéristique indélébile des peuples "créoles" ? Le processus de créolisation est-il toujours à l'œuvre même en contexte néocolonial ? Qu'en est-il de la créolisation dans des sociétés postcoloniales (aux Antilles anglophones, par exemple) qui ont exorcisé leur crise identitaire et qui ont cessé, après avoir acquis une autonomie politique, d'arrimer leur quête identitaire et leur quête de reconnaissance à une rhétorique du ressentiment envers la domination politique et culturelle d'une "Métropole»? Et surtout, que savons-nous des représentations sociales et des multiples variantes de la créolité aux Antilles «françaises" dans les diverses couches de la société ? Tout observateur de la scène martiniquaise, par exemple, est à même de constater l'importance des variantes de la créolité entre les paysans du nord de l'île, les fonctionnaires de Fort-de-France, les élites intellectuelles, les coolies engagés dans la revalorisation de leurs racines indiennes ou les Békés. Et qu'en est-il de la créolité des Martiniquais vivant depuis plusieurs décennies en Métropole? Selon ce premier constat, la question des marqueurs de l'identité créole et des facteurs qui expliquent l'émergence de diverses variantes demeure un enjeu fondamental et incite à élargir les programmes de recherche sur la créolité. 


\section{Créolisation et quête de reconnaissance}

144 La recherche sur la créolisation ne peut se limiter aux seuls "traits culturels » et "significations conscientes » qu'elle sous-tend (Austin-Broos 2007). L'anthropologie doit aussi s'attacher à montrer les sources de son dynamisme. Qu'est-ce qui explique la vitalité, non seulement des productions littéraires et artistiques, mais aussi des multiples associations qui, dans chaque commune, s'investissent dans la promotion de la " culture " créole ? Comment expliquer la vigueur des revendications identitaires et politiques de la Martinique d'aujourd'hui ?

En fait, les cadres théoriques classiques s'avèrent insuffisants pour analyser les moteurs de la créolisation. Les approches culturalistes traditionnelles postulent une rencontre entre «cultures » qui conduirait tout normalement à une hybridation, un métissage ou une copénétration réciproque et symétrique des composantes culturelles, processus qui aboutirait à une nouvelle entité, la créolité, vue comme un produit de l'expérience coloniale. Les approches plus critiques rappellent l'asymétrie des rapports de force entre culture métropolitaine et cultures portées par les groupes issus de l'esclavage ; les moteurs de la créolisation seraient alors la volonté assimilationniste des uns et la résistance culturelle des autres. Quant aux thèses aliénistes, anglo-saxonnes en particulier, elles réduisent la créolisation à un outil idéologique utilisé pour masquer les inégalités de classe ou ethniques; le moteur de la créolisation serait essentiellement politique. Partant des travaux du philosophe et sociologue Axel Honneth sur la reconnaissance, mais aussi de sociologues et d'anthropologues qui s'en inspirent pour analyser les revendications identitaires, nous proposerons ici un modèle complémentaire, qui fait de la quête de reconnaissance le moteur fondamental du processus de créolisation. Cette hypothèse tiendra toutefois compte des deux limites suivantes. Tout d'abord, la quête de reconnaissance collective est un phénomène universel et les revendications martiniquaises pour faire reconnaître leur culture comme "créole " s'inscrivent dans un courant moderne généralisé, aucunement limité aux sociétés créoles. Deuxièmement, les traits culturels et les pratiques sociales créoles ont existé et existeraient, même en l'absence de cette quête de reconnaissance. La culture préexiste au politique. Toutefois, la vigueur de l'affirmation créole et la "créolisation " de l'identité collective martiniquaise, en particulier depuis la départementalisation de 1946, reposent, selon nous, sur une telle quête de reconnaissance. 
Axel Honneth (2000) a proposé une théorie critique voulant que l'absence de reconnaissance sociale d'une communauté envers une autre et le sentiment qui en découle d'être la cible d'un mépris social sapent les conditions normatives de toute communication entre les groupes sociaux concernés. Zygmunt Bauman va plus loin en soulignant que «tout acte qui tend à nier la perception qu'un groupe donné a de ce qu'il est ou de ce qu'il aspire à devenir, à saper les fondements de son mode de vie ou à lui refuser la légitimité dont bénéficient les autres groupes» (2007), est perçu comme humiliant dans les sociétés modernes. Rappelons que, pour Honneth, l'individu est demandeur de reconnaissance sociale dans trois domaines normatifs complémentaires de besoins : la confiance en soi, qui s'inscrit dans les relations intimes avec la personne aimée et l'entourage immédiat; le respect de soi qui passe, entre autres, par des normes juridiques qui reconnaissent des droits à des individus et à des collectivités (communautés de droits); enfin, l'estime sociale indispensable à l'acquisition de l'estime de soi. Ces trois "paliers de reconnaissance" sont en constante interaction et entretiennent des rapports dialectiques dynamiques et créatifs. La quête de reconnaissance devient une lutte continue pour la valorisation symbolique des qualités intrinsèques d'un groupe social, dans le cadre de rapports de pouvoir asymétriques:

«Des expériences individuelles de mépris sont interprétées comme des expériences typiques d'un groupe tout entier, de manière à motiver la revendication collective de plus larges relations de reconnaissance" (Honneth 2000 : 194).

Ce sont ces sentiments collectifs d'injustice et de mépris, ainsi que le nonrespect d'attentes de reconnaissance qui, dans la théorie de Honneth, servent de moteur aux conflits sociaux.

Cherchant à dépasser la théorie critique classique, Honneth déplore les biais utilitaristes des théories des conflits sociaux (y compris ceux $\mathrm{du}$ marxisme) voulant que "les motifs des mouvements de révolte, de protestation et de résistance [soient] transformés, sur le plan catégorial, en "intérêts" résultant de l'inégale répartition des moyens matériels d'existence" (Ibid.: 193). Ces théories ramèneraient, de façon réductrice, les conflits à leur seule dimension de conflits d'intérêt collectifs résultant de l'inégale répartition des richesses. Cette position est aussi celle d'Alain Caillé pour qui une sociologie de la reconnaissance doit dépasser cette lecture instrumentale au profit d'une analyse des mécanismes de revalorisation de l'identité du groupe lui-même, à ses propres yeux et aux yeux des autres (2007b: 208). C'est aussi dans cette perspective 
phénoménologique, qu'il nous faut traiter la quête de reconnaissance des Martiniquais : quête de reconnaissance auprès des Métropolitains, mais aussi quête de valeurs à leurs propres yeux à travers les expressions quotidiennes de la créolité (revalorisation du parler créole dans les médias, valorisation du modèle matrifocal, des lieux de mémoire liés aux luttes anti-esclavagistes). Nous avons pu montrer, à partir d'un terrain approfondi (Massé 2008) et de plusieurs centaines d'entretiens, que c'est au nom de la reconnaissance de la nature proprement «créole » de l'homme antillais que les femmes rejettent les modèles féministes " américains ", que les catholiques rejettent les Églises protestantes nouvelles "étrangères " ou que des psychiatres critiquent les portraits cliniques "européens» inadaptés au cas des schizophrènes et des dépressifs locaux.

Tout en évitant les écueils du misérabilisme ou de l'éloge de la résistance, les sciences sociales se sont efforcées, au cours des dernières décennies, d'utiliser cette théorie de la reconnaissance pour éclairer certaines problématiques (voir, entre autres: Payet \& Battegay, eds 2008 ; Caillé 2007a ; Caillé \& Lazzeri 2009). On parlera même d'un "paradigme» de la reconnaissance qui cohabite avec celui du don : reconnaissance des groupes ethniques minoritaires issus de la migration en contexte de multiculturalisme (Taylor 1994), reconnaissance des minorités autochtones au Canada (Blanchard 2009), reconnaissance de divers groupes sociaux vulnérables (comme les populations des banlieues); mais aussi recherches sur l'épistémologie de la reconnaissance des sujets sur le terrain anthropologique (Fabian 2001) ou analyse des formes d'exacerbation d'un "marché de la reconnaissance ", de la " concurrence des victimes" ou de la «mise en scène des souffrances" (Payet \& Battegay, eds 2008). Certains, comme Stéphane Dufoix (2009), proposent même une typologie à huit niveaux permettant de classer les revendications de reconnaissance face au passé colonial ou esclavagiste d'une nation. Ce paradigme regroupe alors les recherches intéressées par les modalités de fonctionnement, les contextes et les processus qui font de la quête de reconnaissance l'un des moteurs de la créativité associée aux multiples formes de résistance suscitées par les conflits sociaux, politiques et identitaires.

Transposée dans le contexte martiniquais, l'absence de reconnaissance par la Métropole est ressentie par une partie de la population comme du mépris, comme une injustice qui alimente une souffrance réelle et conforte une conscience identitaire (Lucrèce 2000). La reconnaissance juridique des Martiniquais, en tant que sujets de droit, leur reconnaissance politique, en tant que citoyens français, et une radicale amélioration de leur niveau de vie n'ont pas été accompagnées des formes de respect attendues. La construction de l'identité créole découle en ce sens d'une 
lutte pour la reconnaissance dans laquelle les Martiniquais n'agissent plus pour eux-mêmes, comme individus blessés, mais comme membres d'une collectivité discréditée, dévalorisée. Nous allons examiner, ci-dessous, les principales causes de cette quête de reconnaissance (et de la créolité contemporaine), soit le sentiment de dépossession économique et politique, la crise identitaire et la contre-culture du respect compensatoire.

\section{Dépendance économique et politique}

Le premier moteur de la quête de reconnaissance et du processus de créolisation réside dans des violences structurelles qui entretiennent un sentiment de vulnérabilité économique et de dépossession politique. La dépossession des leviers politiques et le confinement de l'économie martiniquaise à l'exportation de matières premières étaient encore plus flagrants à l'époque coloniale. Toutefois, au cours du XXe siècle, des décennies de luttes politiques infructueuses en faveur de pouvoirs politiques régionaux, la prise de conscience d'une dépendance économique des fonds d'aide métropolitains et européens, le mouvement de décolonisation à l'échelle mondiale, voire, a contrario, la vigueur des revendications identitaires de groupes ethniques minoritaires partout dans le monde ont exacerbé les frustrations des Martiniquais. L'hypothèse d'Alain Caillé (2007a) selon laquelle, dans le monde contemporain, les luttes pour une redistribution des droits et des richesses sont devenues prioritairement des luttes de reconnaissance, s'applique parfaitement au cas martiniquais. En fait, rappelle-t-il :

«[... il ne suffit pas de produire et de redistribuer des biens et des services objectifs, matériels, mesurables, pour espérer surmonter toute une série d'autres conflits sociaux qu'on avait crus longtemps secondaires, solubles dans la lutte des classes économiques et qui apparaissent désormais tout à fait irréductibles» (Ibid. : 6).

Certes, les Martiniquais disposent d'un niveau de vie inférieur à celui des Métropolitains, mais il reste élevé comparé à celui d'autres sociétés antillaises anglophones ou hispanophones, voire même par rapport à celui de certains pays membres de l'Union européenne ${ }^{2}$. Le prix à payer est alors un fort sentiment de vulnérabilité face aux paiements de transferts. Les bases de l'économie locale que sont les productions agricoles (banane, sucre) ont été détruites sans que le tourisme ou d'autres secteurs d'activités économiques aient pu prendre la relève. Les exportations ne couvrent alors en 2005 que $16 \%$ des importations (IEDOM 2006). Face à cette

2. En 2002 , le produit intérieur brut per capita atteignait $75 \%$ de la moyenne dans les 25 pays membres de l'Union européenne et était au moins égal à celui de certains des nouveaux membres de l'Union (IEDOM 2006). 
déstructuration profonde, les Martiniquais se sentent dépossédés d'un système économiquement viable et méprisés par une Métropole qui cantonne leur économie à une "économie de comptoir ».

Ce sentiment de précarité économique va de pair avec un sentiment de subordination politique. En dépit des politiques de régionalisation de la fin du XXe siècle, les Martiniquais ont le sentiment de vivre dans une société sans véritables pouvoirs politiques. Les référendums de 2003, puis de 2010 portant sur une autonomie accrue accordée aux collectivités régionales se sont paradoxalement soldés par un rejet massif. Il n'en reste pas moins que le sentiment de vivre dans une société krazé marquée par l'empreinte de son passé colonial et de son présent néocolonial (Armet 1990 : 2004) demeure bien vivace. Pour certains, la départementalisation, qui ne représente qu'une forme de troc de l'égalité des droits en échange d'un «oubli du passé esclavagiste " (Cottias 1997), n'a fait que consacrer un centralisme administratif (Souquet-Basiège 1999), et permet à l'État français d'asseoir sa légitimité en assumant la prise en charge de demandes sociales de plus en plus importantes (Daniel 1997 ; 2007), tout en conservant l'initiative de nouvelles propositions constitutionnelles (Jos 2007).

Le mouvement de révolte et la grève générale déclenchés contre la "profitation ", d'abord en Guadeloupe en janvier puis à la Martinique en février 2009, ont bien exprimé ce ressentiment et la profondeur de la blessure identitaire. Ces conflits ont été "caractérisés par une susceptibilité "à fleur de peau" des grévistes, qui parlent de "dédain" et de "mépris" exercés à leur encontre» (Bonniol 2011: 12) par la France hexagonale. L'histoire des Antilles françaises est, certes, ponctuée de révoltes, de crises, de grèves. Mais il faut reconnaître, avec Christine Chivallon (2009), que ce mouvement "contre la vie chère " a pris une forme tout à fait nouvelle. Ce sont moins le passé esclavagiste ou la départementalisation qui ont été visés, que les formes modernes d'asservissement à une économie artificielle de surconsommation. Surtout, c'est la véhémence des accusations contre les Békés (Blancs autochtones contrôlant l'économie locale) et le racisme affiché dans les relations sociales qui s'imposent dans les dénonciations de la surtarification des biens de consommation. Ce que cette grève générale radicale a apporté de nouveau, c'est la construction d'un "nous collectif » qui s'appuie sur des fondements mémoriels tels que le rappel du passé esclavagiste (Bonniol 2011 : 16) et "une fierté, indéniable, de s'être levé » (Ibid.: 30). Pour Chivallon, "c'est la reconquête d'une confiance en soi dans le champ de la contestation", alimentée par un sursaut d'orgueil créole. Elle a aussi révélé la force du sentiment de vulnérabilité et de fragilité collective qui accompagne le constat de dépendance économique et de subordination politique. De là, les souffrances créées par l'absence de 
reconnaissance des compétences économiques et politiques, et le sentiment d'invisibilité semblent proprement insupportables. C'est sur ce fond de frustration que se greffent la crise identitaire et le ressentiment face à la non-reconnaissance.

\section{Crise identitaire et ressentiment}

Nous avons (Massé 2008) montré que la détresse psychique, l'anxiété ambiante, les tensions dans les relations conjugales, intrafamiliales et de voisinage sont, dans le discours populaire, intimement liées aux blessures identitaires, au ressentiment et à l'absence de reconnaissance. La nonreconnaissance identitaire n'est pas un sujet politique désincarné aux Antilles; elle se présente comme une expérience marquée au sceau des frustrations et de souffrances bien réelles, morales et sociales. Une telle position avait déjà été défendue par Fanon (1952) qui voyait dans la quête de reconnaissance la source structurante des formes de la détresse martiniquaise. Les propos recueillis auprès des professionnels de la santé, prêtres, pasteurs, intellectuels et auprès de la population en général placent cette crise identitaire au cour des explications des détresses individuelles, des conflits interpersonnels et des tensions sociales. L'identité des Martiniquais se trouve fragilisée dans les rapports de genre, les rapports aux religions "étrangères ", les rapports " coloniaux » de couleur, les rapports aux " compatriotes" blancs métropolitains de plus en plus présents sur le territoire martiniquais, mais aussi, par alliances, dans les familles. Or, cette identité martiniquaise postcoloniale est aussi fragilisée tant par la prise de conscience d'un hiatus entre une identité traditionnelle revendiquée par certaines élites et une assimilation au mode de vie européen, que par un discours identitaire empreint d'un profond ressentiment envers le passé esclavagiste de la France coloniale.

Cette amertume est à la fois produit (à travers le sentiment d'échec) et moteur (en alimentant une résilience créatrice) de la créolité martiniquaise. Elle est largement nourrie par les discours dénonçant les méfaits du passé esclavagiste. Les impacts en sont visibles dans les blessures identitaires qui ne manquent pas de s'ouvrir à chaque fois qu'un geste politique est perçu comme l'expression d'un mépris envers la Martinique et son peuple. Et chacune de ces blessures entretient à son tour un ressentiment qui s'inscrit, insidieusement, dans l'identité et la mémoire collective d'une fraction de la population. Ce ressentiment peut être vu comme le principal symptôme d'une pathologie de la reconnaissance, elle-même inscrite au cœur de la détresse individuelle et collective. Si le poids de cet écrasement colonial est toujours ressenti à travers les espoirs de réparations, le sentiment d'injustice et le ressentiment envers l'exploitation 
coloniale, il s'exprime tout autant, mais positivement cette fois, à travers la résilience culturelle, la créativité, la vigueur du politique, l'engagement social qui marquent les jalons d'une quête de reconnaissance constructive.

Toutefois, pour certains, l'entretien d'une mémoire collective sur le passé colonial risque d'amener la quête identitaire sur des sentiers dangereux s'il est mis au service de la construction de simples «mythes compensateurs et unificateurs» (Théodore 2000 : 18). Pour ne pas s'enliser dans une lecture victimaire de l'histoire, une rhétorique du ressentiment, et surenchérir dans les demandes de "réparations ", les Créoles martiniquais devront définir le seuil minimum de reconnaissance et les composantes centrales de la créolité qu'ils souhaitent voir reconnus. Quels sont les éléments de cette "identité communautaire partagée " et de cette "solidarité culturelle» invoquées par Ozier-Lafontaine (1999), sur lesquelles une estime de soi collective pourra se développer? Ces questions nous ramènent aux enjeux de définition de la «nature », des "pourtours » de la créolité martiniquaise que nous avons évoqués en première partie de ce texte.

L'influence de la crise identitaire comme moteur de la créolisation doit être pondérée par au moins trois constats. Premièrement, tout en soutenant que la «crise identitaire» martiniquaise est l'un des moteurs de la créolisation, une anthropologie de la créolisation doit être prudente face à toute essentialisation de ce concept. La notion de crise réfere ici à un processus constant, jamais achevé, de pondération du poids relatif de chacune des composantes de l'identité collective. Ainsi, en dépit d'une revitalisation de l'usage de la langue créole, de l'enseignement des traditions et de la vigueur de la production artistique d'inspiration créole, le risque d'une folklorisation de la culture créole est bien présent (Price 2000). La crainte exprimée par Édouard Glissant (1981) redoutant que la colonisation française atteigne le "stade suprême» de toute colonisation, soit la dépersonnalisation complète d'une communauté demeure fondée. Deuxièmement, la notion de crise n'est pas négative. Dans le monde moderne, une identité collective ne peut être stabilisée et se vivre en réclusion. Ces identités sont toujours contestées de l'intérieur en fonction des lectures divergentes qu'en auront divers sous-groupes sociaux et politiques. Elles sont exposées à de multiples autres identités collectives et aux pressions de la mondialisation. Autrement dit une identité qui n'est pas en crise est une identité morte. Enfin, troisièmement, souligne Deirdre Meintel (2008), il faut être prudent en associant identité ethnique et reconnaissance, chaque individu ayant tendance à combiner des identités multiples et à chercher une reconnaissance pour chacune d'entre elles. Cette réserve s'applique aux Martiniquais, préoccupés autant de leur reconnaissance comme Européens, Antillais et Français, que comme Martiniquais. 
Au-delà des analyses politique, éthique et juridique de la reconnaissance officialisée et institutionnalisée de l'identité martiniquaise, nous devons aborder la quête de reconnaissance comme processus génératif, engagement créatif. L'intérêt pour l'anthropologue est moins l'aboutissement $\mathrm{du}$ processus (être reconnus comme Martiniquais) que le processus de définition du soi collectif comme créole. En fait, c'est à la fois de l'intérieur et de l'extérieur que viendra la reconnaissance. Ce processus est donc dialogique; dialogue avec l'autre perçu comme source de mépris, mais dialogue avec soi quant à ses propres multiples identités paradoxales et contradictoires. La reconnaissance est d'abord une reconnaissance du dedans s'exprimant par l'actualisation des savoirs et pratiques créoles. Il faut d'abord être visible pour soi, avant de souhaiter l'être pour l'autre. Et c'est de cette difficile négociation avec soi et avec l'autre que naît la détresse créole qui alimente à son tour la crise identitaire.

\section{Contre-culture du respect compensatoire et paradoxes}

L'effervescence dans la créativité créole relève en partie, à l'instar de ce que Honneth a observé pour certains groupes sociaux, d'une forme de " contre-culture du respect compensatoire corrigeant par une stylisation démonstrative une appréciation jugée injuste de leurs qualités collectives " (Honneth 2000 : 151). La quête de reconnaissance est aussi une quête constructive de respect qui passe par la valorisation des produits historiques de la créolité et par une intense créativité. Et c'est en cela que la quête de reconnaissance devient un moteur fondamental du processus de créolisation. Elle alimente une fierté certaine et légitime devant les réalisations culturelles, dans les domaines de la littérature, de la chanson, de la danse ou des arts plastiques. La Martinique d'aujourd'hui vit, de plus, au rythme d'une revitalisation culturelle passant par les appels au devoir de mémoire, à la multiplication des commémorations (en particulier la vivacité des débats qui ne manquent pas d'entourer, chaque année, les fêtes de commémoration de l'abolition de l'esclavage). Cette créativité se manifeste par la multiplication d'activités artistiques publiques, scolaires ou politiques, régionales et communales. Ce devoir de mémoire joue un rôle constructif et essentiel dans la dynamisation du processus de créolisation aujourd'hui. Mais, comme le soulignait Edouard Glissant en marge de la fondation du Centre national pour la mémoire de l'esclavage, la mémoire collective peut aussi susciter inquiétude et tourment; parfois elle peut être négative si elle n'est pas "délivrée des interdits et des séductions et des indifférences et des provocations et des mépris incontrôlables» (2007: 176). 
De même, cette contre-culture créative passe par une certaine idéalisation de la vie familiale, communautaire et culturelle traditionnelle; une société «fraternelle faite de solidarité, qui trouvait son équilibre à travers des normes, des rites, des mythes, des croyances, des superstitions propres " (Armet 2004 : 42), marquée par les figures emblématiques de la mère poteau-mitan, du Nègre marron et du Béké exploiteur. Cette idéalisation du passé, omniprésente dans la production littéraire martiniquaise des dernières décennies cohabite avec une critique acerbe des méfaits du colonialisme et de la départementalisation. Certains en appellent à un dépassement de ces reconstructions du passé qui «fonctionnent comme des extrapolations, comme des superstitions qui tendent à protéger d'un monde - le monde moderne - qui effraie» (Lucrèce 2000 : 14-15), voire au dépassement des catégories classiques (dominants/dominés, intégration, assimilation, métissage, société postcoloniale/néocoloniale) qui ne permettent plus de saisir la complexité de la crise identitaire et politique aujourd'hui (Affergan 2002).

Cette créativité ne conduit pas nécessairement à un système articulé de valeurs et ne passe pas automatiquement par un programme cohérent d'actions politiques. La profonde interpénétration entre valeurs créoles et françaises de même que l'ambivalence des discours autonomistes en sont des manifestations patentes. En fait, la quête de reconnaissance identitaire évolue à travers divers paradoxes et ambivalences, voire sous forme d'une « ambivalence socialisée » dans laquelle Melville Herskovits voyait, déjà en 1937, une déchirure identitaire collective. La dimension paradoxale de la société martiniquaise a aussi frappé William Miles (1992) qui parlait d'un "paradoxe au paradis" pour désigner non seulement les contradictions entre le niveau de vie élevé et le niveau de ressentiment face aux structures postcoloniales, mais aussi pour désigner les déchirures entre des identités à la fois française et martiniquaise, francophone et créolophone, tiers-mondiste et européenne. Nous avons pu (Massé 2008) greffer à ce diagnostic d'autres paradoxes, comme l'omniprésence d'une détresse existentielle cohabitant avec un remarquable dynamisme communautaire, culturel et politique; de la fierté des droits acquis et un profond ressentiment face au prix politique qu'il a fallu payer. Paradoxe fondamental aussi du processus de créolisation lui-même alors que "les cultures créoles sont stabilisées dans un état d'ouverture " (Stoddard \& Cornwell 1999 : 338) et que l'identité créole préfigurant le Tout-Monde, se disant ouverte, présente aussi un risque d'essentialisme identitaire fondé sur la réification de traits culturels créoles et de dérives sectaires, racistes ou xénophobes (Giraud 1997). L'un des moteurs du processus de créolisation se trouve dans les tensions qui découlent de ces paradoxes et ambivalences. Si toutes 
les sociétés modernes vivent une forme ou une autre d'hybridation culturelle, les paradoxes et ambivalences invoqués ici, sans la résumer, font de la créolisation, la forme d'hybridation culturelle proprement adaptée aux sociétés antillaises francophones.

Lorsque James Clifford (1988) lança sa formule désormais classique selon laquelle "nous sommes tous créoles maintenant dans nos propres archipels urbains ", il ouvrait la voie à l'extension du concept de créolisation pour en faire la métaphore de l'intensification et de la mondialisastion des contacts interculturels, des métissages. Nous avons soutenu, ici, qu'il serait vain de nier son potentiel métaphorique ou de vouloir en interdire un usage extensif. Toutefois, le concept d'hybridation culturelle, plus neutre, universel, nous semble mieux adapté pour rendre compte des divers modes et niveaux de métissages culturels issus des contacts de culture à travers le temps et l'espace. Le processus de créolisation, et ses produits que sont les créolités (martiniquaise, guadeloupéenne, réunionnaise, guyanaise, etc.), est l'une des formes que peut prendre ce processus générique d'hybridation. Le concept de créolisation, pour sa part, sera d'autant plus opératoire qu'il référera à des conditions historiques (esclavage, économie de plantation, métropoles européennes), des populations en présence (principalement d'origines africaines, indiennes et européennes), des rapports de couleur asymétriques et des impérialismes culturels qui sont propres à des mondes créoles. La quête de reconnaissance, elle-même stimulée par le sentiment de dépendance économique et politique, par une crise identitaire marquée par le ressentiment et par une contre-culture du respect, a été présentée ici comme étant plus adaptée que les théories classiques pour rendre compte de la reproduction des tensions sociales et politiques, et surtout des orientations de la créativité de la créolité. Cette approche centrée sur la quête de reconnaissance nous permet de soulever d'autres questions. Quels sont donc les objets qui sont principalement source de mépris et qui, à l'inverse, commanderaient une reconnaissance valorisante et donc compensatrice? Pour quelles qualités, quelles réalisations, quelles performances les Martiniquais souhaitent-ils être mieux reconnus? Et de qui attend-on principalement une telle reconnaissance? Les réponses à ces questions relèvent plus de la politique et des choix de société que d'un énième programme de recherche en sciences sociales. 
MOTS CLÉS/KEYWORDS : créolisation/creolization - créolité/creolity - reconnaissance/recognition - Martinique - crise identitaire/identity crisis.

\section{BIBLIOGRAPHIE}

Affergan, Francis

2002 "Vers une anthropologie du postcolonialisme? ", Ethnologie française 4 : 581-588

[http://www.culture.gouv.fr/sef/revue/ 02_4/02_4_01r.htm].

\section{Allen, Carolyn}

1998 "Creole Then and Now:

The Problem of Definition ", Caribbean

Quaterly 44 (1-2) : 33-49.

\section{Armet, Auguste}

1990 Société et santé à la Martinique.

Le système et le masque. Paris-Dakar,

Présence africaine.

\section{Austin-Broos, Diane}

2007 "Comments on Khan's Text", Current Anthropology 48 (5) : 666-667.

Baumann, Zygmunt

2007 «Entretien», Le Point, 26 juillet.

Bernabé, Jean, Patrick Chamoiseau

\& Raphaël Confiant

1989 Éloge de la créolité. Paris, Gallimard.

Bibeau, Gilles

1997 «Cultural Psychiatry in a Creolizing World : Questions for a New Research Agenda ", Transcultural Psychiatry 34 (1) : 9-41.

\section{Blanchard, Martin}

2009 «Habermas chez les autochtones: droits collectifs et reconnaissance", in André Caillé \& Christian Lazzeri, eds, La Reconnaissance aujourd'hui... : 143-170.

Bonniol, Jean-Luc

2006 «Situations créoles, entre culture et identité ", in Carlos A. Célius, ed., Situations créoles... : 49-57.
2011 "Janvier-mars 2009, trois mois de lutte en Guadeloupe ", Les Temps Modernes 662-663: 82-113.

Browne, Katherine E.

2004 Creole Economics. Caribbean Cunning under the French Flag.

Austin, University of Texas Press.

Burton, Richard

1993 "Ki moun nou yé? The Idea of Difference in Contemporary French West Indian thought ", New West Indian Guide 67 (1-2) : 5-32.

Caillé, Alain, ed.

2007a La Quête de reconnaissance.

Paris, La Découverte.

2007b "Reconnaissance et sociologie", in La Quête de reconnaissance... : 185-208.

Caillé, Alain \& Christian Lazzeri, eds 2009 La Reconnaissance aujourd'hui. Paris, Éd. du CNRS.

Célius, Carlos A., ed.

2006 Situations créoles.

Pratiques et représentations.

Québec, Nota Bene («Société»).

\section{Chamoiseau, Patrick}

1998 "Cent cinquantenaire de l'abolition de l'esclavage, 1848-1998 ", France-Antilles, cahier spécial, 20 mai.

\section{Chaudenson, Robert}

2001 Creolization of Language and Culture. London, Routledge.

Chivallon, Christine

2009 "Guadeloupe et Martinique en lutte contre la "profitation" : du caractère nouveau d'une histoire ancienne " [http://www.lam.sciencespobordeaux.fr/ pageperso/guadeloupe_et_martinique.pdf].

\section{Raymond Massé}


Clifford, James

1988 The Predicament of Culture.

Twentieth-Century Ethnography, Literature and Art. Cambridge,

Harvard University Press.

Cottias, Myriam

1997 «L'oubli du passé

contre la citoyenneté : troc et ressentiment à la Martinique (1848-1946)", in Fred

Constant \& Justin Daniel, eds, 1946-1996.

Cinquante ans de départementalisation

Outre-mer. Paris, L'Harmattan : 293-314.

Daniel, Justin

1997 «L'espace politique martiniquais à l'épreuve de la départementalisation", in Fred Constant \& Justin Daniel, 1946-

1996. Cinquante ans de départementalisation

Outre-Mer. Paris, L'Harmattan : 223-260.

Daniel, Justin, ed.

2007 L'Outre-mer à l'épreuve de la décentralisation. Nouveaux cadres institutionnels et difficultés d'adaptation. Paris, L'Harmattan

Dufoix, Stephane

2009 «Connaître et reconnaître le passé :

huit dimensions des politiques de reconnaissance ", in Alain Caillé \& Christian Lazzeri, eds, La Reconnaissance aujourd'hui... : 87-114.

Fabian, Johannes

2001 Anthropology with an Attitude.

Critical Essays. Stanford,

Stanford University Press.

Fanon, Frantz

1952 Peau noire, masques blancs.

Paris, Le Seuil.

\section{García Canclini, Néstor}

1995 Hybrid Cultures. Strategies for Entering and Leaving Modernity.

Transl. by Christopher L. Chiappari \& Silvia L. López. Foreword by Renato Rosaldo. Minneapolis, University of Minnesota Press.
Glissant, Édouard

1981 Le Discours antillais. Paris, Le Seuil.

1995 "Creolization in the Making

of the Americas ", in Vera Lawrence Hyatt

\& Rex Nettleford, eds, Race, Discourse,

and the Origin of the Americas.

A New World View. Washington,

Smithsonian Institution Press : 268-275.

1997 Poétique, 4. Traité du tout-monde.

Paris, Gallimard.

2007 Mémoires des esclaves.

Paris, Gallimard («NRF »).

Hannerz, Ulf

1987 "The World in Creolization", Africa, Journal of the International African Institute 57 (4) : 546-559.

\section{Harris, Roxy \& Ben Rampton}

2002 «Creole Metaphors in Cultural

Analysis: On the Limits and Possibilities of (Socio)Linguistics ",

Critique of Anthropology 22 : 31-51.

Herskovits, Melville J.

1937 The Myth of the Negro Past.

New York, Harper \& Bros.

Hintzen, Percy

2002 "The Caribbean : Race and Creole Ethnicity ", in David Theo Goldberg \& John Solomos, eds, A Companion to Racial and Ethnic Studies. Oxford, Blackwell : 475-494.

Honneth, Axel

2000 La Lutte pour la reconnaissance.

Paris, Le Cerf.

2006 "Avant-propos ", in Axel Honneth,

La Société du mépris. Vers une nouvelle

théorie critique. Paris, La Découverte :

35-38.

Institut d'émission des départements

d'Outre-Mer (IEDOM)

2006 La Martinique en 2005.

Paris, Éd. de l'IEDOM. 
Jos, Emmanuel

156
2000 "Quelques réflexions sur le statut constitutionnel des DoM-Rom après

la révision du 28 mars 2003 ", in Justin

Daniel, ed., L'Outre-mer à l'épreuve

de la décentralisation... : 31-54.

Khan, Aisha

2001 «Journey to the Center of the Earth :

The Caribbean as Master Symbol ", Cultural Anthropology 16 (3) : 271-302.

2007 "Good to Think: Creolization, Optimism and Agency ", Current Anthropology 48 (5) : 653-666.

Kleinman, Arthur

1997 "On Gilles Bibeau’s Creolizing World », Transcultural Psychiatry 34 (1) : 72-77.

\section{Lowenthal, David}

1972 West Indian Societies. Oxford, Oxford University Press.

Lucrèce, André

2000 Souffrance et jouissance aux Antilles. Trinité (Martinique), Gondwana Éd.

\section{Massé, Raymond}

2008 Détresse créole. Ethno-épidémiologie de la détresse psychique à la Martinique. Québec, Presses de l'Université Laval.

Meintel, Deirdre

2008 «Identités ethniques plurielles et reconnaissance connective en Amérique du Nord ", in Jean-Paul Payet \& Alain Battegay, eds, La Reconnaissance à l'épreuve. Explorations socio-anthropologiques.

Villeneuve d'Ascq, Presses universitaires du Septentrion : 311-319.

Miles, William

1992 Paradoxe au paradis. De la politique à la Martinique. Trad. de l'américain par Loïza Nellec-Miles.

Paris, L'Hamattan.
Orlave, Benjamin

2007 «Editorial: Current Approaches to Hybridity ", Current Anthropology 48 (5) :

631-632.

Ozier-Lafontaine, Louis-Félix

1999 Martinique: la société vulnérable.

Trinité (Martinique), Éd. Gondwana.

\section{Palmié, Stephan}

2006 "Creolization and its Discontents", Annual Review of Anthropology 35 : 433-456.

Payet, Jean-Paul \& Alain Battegay, eds 2008 La Reconnaissance à l'épreuve. Explorations socio-anthropologiques. Villeneuve d'Ascq, Presses universitaires du Septentrion.

\section{Payet, Jean-Paul \& Alain Battegay}

2008 «La reconnaissance, un concept de philosophie politique à l'épreuve des sciences sociales", in Jean-Paul Payet \& Alain Battegay, La Reconnaissance à l'épreuve... : 23-42.

\section{Perret, Delphine}

2001 La Créolité: espace de création. Matoury, Ibis Rouge.

\section{Price, Richard}

2000 Le Bagnard et le Colonel.

Trad. de l'américain par Sally Price. Paris, Presses universitaires de France («Ethnologies»).

\section{Souquet-Basiège, Pierre}

1999 Le Malaise créole. Un dérivé du mal français. Petit-Bourg, Ibis Rouge.

\section{Stoddard, Eye \& Grant H. Cornwell}

1999 "Cosmopolitan or Mongrel?

Creolité, Hybridity, and "Douglarisation" in Trinidad ", European Journal of Cultural Studies 2: 331-353. 
Théodore, Jean-Marie

2000 Identité et culture. Considérations intempestives sur la culture caribéenne.

Case-Pilote, Lafontaine / Paris,

New légend Éd.
Tylor, Charles

1994 "The Politics or Recognition", in A. Gutmann, ed., Multiculturalism.

Princeton, Princeton University press : 25-73.

\section{RÉSUMÉ/ABSTRACT}

Raymond Massé, Créolisation et quête de reconnaissance. - Utilisé comme métaphore des multiples formes de métissage racial et culturel, le concept de créolisation risque de perdre toute valeur comme outil analytique des formes originales d'hybridation culturelle propres aux sociétés créoles. Nous proposerons ici de le réserver pour traduire les formes originales de contacts culturels entre les métropoles européennes et les populations africaines asservies dans le cadre des «sociétés de plantation». Toutefois, la réhabilitation de ce concept passe à notre avis par deux chantiers de recherche peu ou mal explorés. Le premier est celui d'une anthropologie politique de la créolisation qui saura apporter des réponses à une série de questions (im)pertinentes sur sa nature, ses objets, ses déclinaisons dans le temps et dans les diverses sphères de la vie quotidienne. Le second chantier visera à identifier le moteur premier de ce processus. Nous suggérerons alors, dans la foulée de la théorie critique d'Axel Honneth, qu'en contexte martiniquais, c'est la quête de reconnaissance identitaire qui lui fournit son énergie créative vitale.
Raymond Massé, Creolization and the Quest for Recognition. - Used as a metaphor for many forms of racial and cultural mixing, creolization risks losing its value as a tool for analyzing the original forms of cultural hybridization typical of creole societies. The proposal is made to restrict this concept to the initial forms of cultural contact between European powers and enslaved Africans in "plantation societies». Rehabilitating this concept calls for research in two seldom or poorly explored areas. The first is the political anthropology of creolization, which might provide answers to several (im)pertinent questions about the nature of this phenomenon, its varieties over time and in various spheres of everyday life. The second line of research should seek to identify the driving force in this process. The suggestion is made, in line with Axel Honneth's critical theory, that this driving force is, in Martinique, a quest for the recognition of an identity: this is what generates its creative vitality. 